\title{
The use of the forceps biopsy as an auxiliary technique for the visualization of the major duodenal papilla using the foward-viewing upper endoscopy
}

\author{
Nathalia Saber de ANDRADE ${ }^{1}$, Ana Maria Félix ANDRÉ ${ }^{1}$, Victor Hugo Perches FERREIRA² and \\ Lincoln Eduardo Villela Vieira de Castro FERREIRA ${ }^{1}$
}

Received 7/7/2017 Accepted 11/9/2017

\begin{abstract}
Background - Conventional esophagogastroduodenoscopy is the best method for evaluation of the upper gastrointestinal tract, but it has limitations for the identification of the major duodenal papilla, even after the use of the straightening maneuver. Side-viewing duodenoscope is recommended for optimal examination of major duodenal papilla in patients at high risk for lesions in this region. Objective - To evaluate the use of the biopsy forceps during conventional esophagogastroduodenoscopy as an additional tool to the straightening maneuver, in the evaluation of the major duodenal papilla. Methods - A total of 671 patients were studied between 2013 and 2015, with active major duodenal papilla search in three endoscope steps: not straightened, straightened and use of the biopsy forceps after straightening. In all of them it was recorded whether: major duodenal papilla was fully visualized (position A), partially visualized (position B) or not visualized (position C). If major duodenal papilla was not fully visualized, patients continued to the next step. Results - A total of 341 were female (50.8\%) with mean age of 49 years. Of the 671 patients, 324 (48.3\%) major duodenal papilla was identified in position A, $112(16.7 \%)$ in position B and $235(35 \%)$ in position C. In the 347 patients who underwent the straightening maneuver, position A was found in $186(53.6 \%)$, position B in $51(14.7 \%)$ and position C in $110(31.7 \%)$. Of the 161 remaining patients and after biopsy forceps use, position A was seen in 94 (58.4\%), position B in 14 (8.7\%) and position C in $53(32.9 \%)$. The overall rate of complete visualization of major duodenal papilla was $90 \%$. Conclusion - The use of the biopsy forceps significantly increased the total major duodenal papilla visualization rate by $14 \%$, reaching $604 / 671(90 \%)$ of the patients $(P<0.01)$ and it can be easily incorporated into the routine endoscopic examination of the upper gastrointestinal tract.
\end{abstract}

HEADINGS - Ampulla of Vater, physiopathology. Adenocarcinoma, diagnosis. Digestive system endoscopy, utilization.

\section{INTRODUCTION}

Conventional esophagogastroduodenoscopy (EGD) is currently the best method for evaluation of the upper gastrointestinal tract, which is usually visualized from the esophagus down to the second duodenal part. However, it is not always possible to completely identify the major duodenal papilla (MDP) with the forward-viewing gastroscopy ${ }^{(1)}$. The full examination of the MDP is essential for the early detection of ampullary and periampullary lesions during screening and follow up of patients at high risk for adenocarcinoma ${ }^{(2)}$. While American Society for Gastrointestinal Endoscopy recommends the use of side-viewing duodenoscopes for optimal examination of the MDP, this type of endoscope is not available in most private ambulatory endoscopy units ${ }^{(3)}$.

Previous studies demonstrate limitations of the forwardviewing endoscopes for complete examination of the MDP. Such studies resulted in $24 \%$ to $80.8 \%$ full visualization of the MPD.
Both, the straightening maneuver, commonly carried out during the endoscopic retrograde cholangiopancreatography (ERCP), and the use of transparent caps fitted to the tip of forward-viewing gastroscopes have improved the full visualization of the MDP. However, the straightening maneuver has only enabled the full identification of MDP in $54.7 \%$ of patients studied, and the use of cap-fitted gastroscopes, while more efficient, is restricted to EGDs with the specific purpose of evaluating the $\operatorname{MDP}^{(1,4,5)}$.

The ideal solution would be an easy and inexpensive method that could be used in all routine EGD, with high rates of MDP complete visualization. Based on such prerogatives, this study has evaluated the use of the biopsy forceps during conventional EGD as an additional tool to the straightening maneuver in the identification of MDP.

The objective of the study is to evaluate the use of the biopsy forceps during conventional EGD as an additional tool to the straightening maneuver, for complete examination of the MDP. 


\section{METHODS}

A transversal study with patients from the Gastroenterology outpatient clinic of the University Hospital of the Universidade Federal de Juiz de Fora (UFJF) or from the Unified Health System (SUS, for the acronym in Portuguese) to undergo esophagogastroduodenoscopies for the investigation of signs or symptoms related to upper GI disorders.

Only ASA 1 and 2 patients were invited to participate in the study. Patients have undergone EGD at the Digestive Endoscopy Unit of UFJF's University Hospital, 1 day per week, from September 2013 to November 2015. All procedures were carried out by an advanced fellow, trained to perform the straightening maneuver, with thorough knowledge of MDP morphology, together with an experienced endoscopist, fully trained to perform ERCP, with the use of 44000 series processors and 530 and 590 Fujinon gastroscopes. Patients were sedated with midazolam $(1-2 \mathrm{mg})$ and fentanyl $(25-50 \mu \mathrm{g})^{(6)}$. When necessary, propofol $(10-50 \mathrm{mg})$ was additionally administered in individual cases, in order to facilitate patients' collaboration with the study. During the procedures, all patients received supplemental $\mathrm{O}_{2}(3 \mathrm{~L} / \mathrm{min})$ and had their $\mathrm{SaO}_{2}$ and blood pressure monitored. The total time of procedure was not recorded and observations exclusively considered data referring to the visualization of the MDP.

The study excluded patients with obstructions in the antropyloric region; bulbar stricture or any other lesion that could limit access to the second duodenal part; patients with a previous case of upper gastrointestinal tract surgical intervention; patients in full-dose anticoagulant therapy and those who refused to participate in the protocol after reading the Free and Informed Consent Form.

\section{Examinations were carried out under the following proce- dures}

1. Full examination of esophagus, stomach and duodenum with active search for MDP in the second duodenal part with a conventional non-straightened endoscope.

2. Identification of MDP with a non-straightened device: fully visualized (position A), partially (position B) or not visualized (position C). Patients whose papilla was fully visualized were not submitted to auxiliary maneuvers and were included in Group 1. When MDP was partially identified or not visualized, patients continued to the next stage.

3. Straightening maneuver with new active search for MDP.

4. New identification of MDP after straightening in the second duodenal part: fully visualized (position A), partially (position B) or not visualized (position C). Patients whose MDP was partially visualized or not identified continued to the third stage. Patients whose papilla was fully visualized were included in Group 2.

5. Use of the biopsy forceps to push back or laterally displace the duodenal folds, for better MDP visualization.

6. Last identification of MDP with the biopsy forceps: fully visualized (position A), partially (position B) or not visualized (position C). Patients with fully visualized MDP were included in Group 3. MDP.

The FIGURES 1 and 2 show the different positions of the

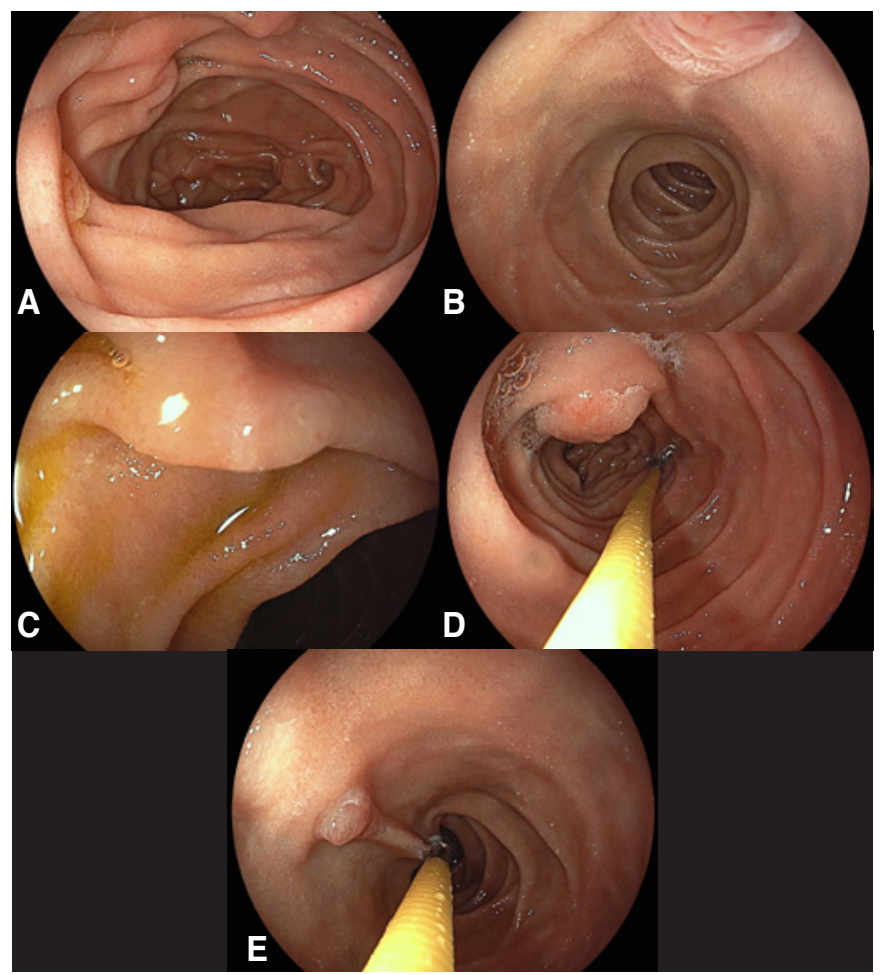

FIGURE 1. A-E.

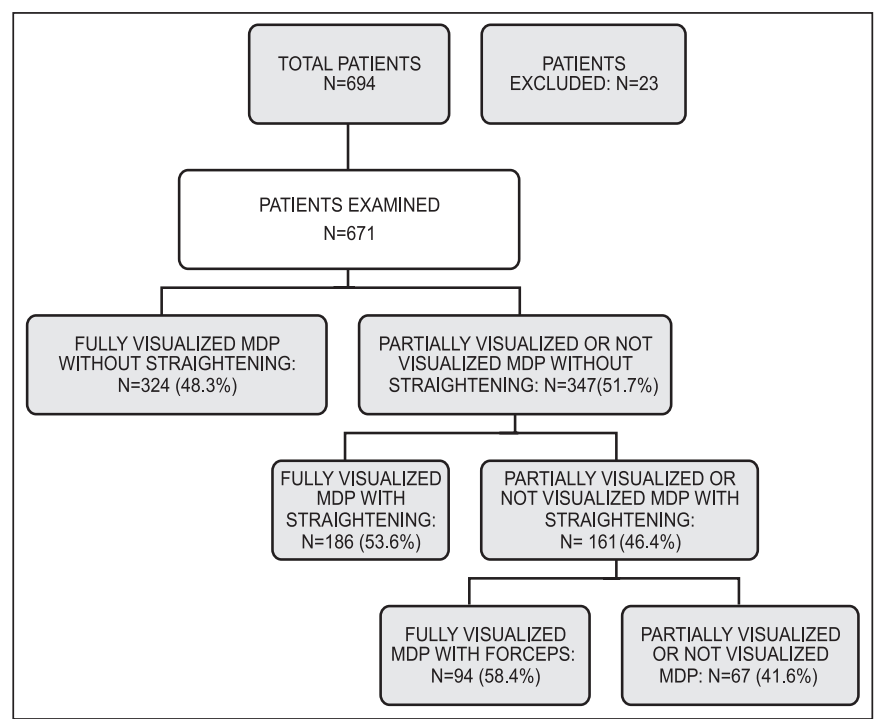

FIGURE 2. Endoscopic results found following the research design. MDP: major duodenal papilla.

Data collected were recorded in specific forms for each patient and evaluated with the use of the 5.0 GraphPad Prism software. The hypothesis test was used to verify if MDP full visualization rates with the use of the biopsy forceps were proven to be higher than results obtained without biopsy forceps. $P<0.05$ values were considered statistically significant. The study was approved by the Ethics Committee of UFJF's University Hospital and registered at Plataforma Brasil under the number 01796512.5.0000.5147. 


\section{RESULTS}

Of the 695 patients invited to participate in the study, four of them refused to join the research and two were fully anticoagulated. Other 17 were excluded due to the presence of lesions that would make the access to the second duodenal part impossible and/or due to previous surgical intervention with anatomical changes. Of the remaining 671 patients, 341 were female $(50.8 \%)$ and 330 male $(49.2 \%)$. The age range varied from 18 to 80 years old (mean age of 50 years old). The sequence followed by the research and results obtained are in FIGURE 2.

Group $1(n=671)$ shows the following results: position A in 324 $(48.3 \%)$ patients, position B in $112(16.7 \%)$ and position C in 235 $(35 \%)$. In Group 2, 347 patients were submitted to the straightening maneuver. Among them, position A was identified in $186(53.6 \%)$ patients, position B in $51(14.7 \%)$ and position C in $110(31.7 \%)$. In group 3, the biopsy forceps was used to active search for the MDP in the remaining 161 patients. Within this group, position A was identified in $94(58.4 \%)$, position B in $14(8.7 \%)$ and position $\mathrm{C}$ in $53(32.9 \%)$ patients.

Considering only MDP full visualization in sequence, position A was observed in $324(48.3 \%)$ patients of group 1, $186(27.7 \%)$ of group 2 and 94 (14\%) of group 3, with a total of 604 of the 671 patients examined $(90 \%)$. Comparing the number of fully visualized MDP without biopsy forceps (510/671 - 76\%) versus the number of fully visualized MDP with the use of the biopsy forceps (604/761 $90 \%$ ), the result is $P<0.01$. During the study, there were two papilla lesions identified - one adenoma and one lymphoma.

\section{DISCUSSION}

MDP can be the site for several benign and malign lesions ${ }^{(7-10)}$. However, due to its anatomic position in the posteromedial wall of the descending duodenum, the forward-viewing device has some limitations, both in the identification and examination of the $\mathrm{MDP}^{(1,11)}$. The duodenoscope side-viewing is recommended for optimal evaluation of the MDP. Nonetheless, such kind of endoscope is not available in most outpatient digestive endoscopy units and is almost exclusively found in hospital units performing $\mathrm{ERCP}^{(3)}$.

The rates of full MDP visualization with conventional EGD have shown great variation in the few studies published, as demonstrated below. (TABLE 1).

TABLE 1. Description of MDP visualization with EGD

\begin{tabular}{|c|c|c|c|c|c|c|c|}
\hline Study & N. & $\begin{array}{c}\text { MDP } \\
\text { FV }\end{array}$ & $(\%)$ & $\begin{array}{l}\text { MDP } \\
\text { PV }\end{array}$ & $(\%)$ & $\begin{array}{l}\text { MDP } \\
\text { NV }\end{array}$ & $(\%)$ \\
\hline Hew WY $Y^{(1)}$ & 338 & 185 & 54.7 & 117 & 34.6 & 36 & 10.7 \\
\hline Choi YR ${ }^{(5)}$ & 120 & 97 & 80.8 & 13 & 10.8 & 10 & 8.4 \\
\hline Abdelhafez $\mathbf{M}^{(4)}$ & 101 & 24 & 23.8 & 45 & 44.5 & 32 & 31.7 \\
\hline $\begin{array}{l}\text { Andrade } \\
\text { NS }^{\text {(present study) }}\end{array}$ & 671 & 510 & 76 & 51 & 7.6 & 110 & 16.4 \\
\hline
\end{tabular}

MDP: major duodenal papilla; EGD: esophagogastroduodenoscopy; FV: full visualization; PV: partial visualization; NV: not visualized.
Our MDP full visualization rate with forward-viewing gastroscopy was $76 \%$ versus $80.8 \%$ in study $2,54.7 \%$ in study 1 and only $23.8 \%$ in study 3 . Nevertheless, study 1 did not perform the straightening maneuver in 81 patients in which the MDP was partially visualized, and only performed it in 144 patients whose MDP was not identified. In those 144 patients, the straightening maneuver improved the full identification of the MDP in $77(50 \%)$ patients. If the same rate was applied to the 81 patients in which the MDP was partially visualized and the straightening maneuver was not performed, we would have at least 40 new cases of fully visualized MDP which, if added to the 185 described in the study, would reach 225 patients or $74.5 \% \%^{(1)}$. The MDP full visualization rate would then be really close to the values found in our study $(76 \%)$ and in study $2(80.8 \%)$. Only study 3 presented a very low MDP full visualization rate with conventional EGD $\left(23.8^{\%} \%\right)^{(4)}$. The reasons for such difference in MDP visualization rates could lie in the professional performing those procedures, considering that only $44 \%$ of endoscopic examinations in study 3 were performed by ERCP-trained endoscopists. In this study, ERCP-experienced endoscopists were able to locate the MDP during conventional EGD in a significantly higher number than non ERCP-trained endoscopists $(80 \%$ vs $60 \% P=0.033)$. In studies 1 and 2 , all examinations were carried out by ERCP-trained endoscopists. In our study, all procedures were performed by advanced fellows, together with ERCP-experienced staff. Another reason for such low success rates in study 3 could be the time established for MDP search. The study defined a maximum of 2 minutes after trespassing the pylorus to locate the MDP, whereas in other studies, including ours, there was no definition of a minimum time for MDP search.

The straightening maneuver with forward-viewing gastroscopy described in study 1 by Hew WY et al. ${ }^{(1)}$ improves MDP detection rate, which was also observed in our study. Similarly to study one, in which the straightening maneuver increased MDP full visualization rate by $50 \%$, in our study, the maneuver increased MDP full visualization rate by $53.6 \%$ (FIGURE 2).

Even though the cap-assisted endoscopy technique, which requires the use of a transparent cap fitted to the tip of the endoscope for manipulation of duodenal folds and better exposure of MDP, may be highly effective for the full detection of the MDP, it will requires additional examination. Unless patients have previous indication for MDP study and cap-assisted endoscopy with forward-viewing EGD, it will be necessary to remove the endoscope in order to insert the cap and reintroduce it for MDP evaluation. Studies 2 and 3 used the cap for MDP identification. In study 2, the MDP full visualization rate with $4 \mathrm{~mm}$ cap was $98 \%$ (118 out of 120 patients) and reached $100 \%$ with the use of an $11 \mathrm{~mm} \mathrm{cap}^{(5)}$. In study 3, the MDP full visualization rate was $97 \%$ (98 out of 101 patients). In our study, the use of the biopsy forceps increased the MDP full visualization rate by $14 \%$, reaching 604 of 671 patients examined $(90 \%)^{(4)}$.

The advantage demonstrated in our study is exactly the fact that our technique for MDP examination can be used in all patients submitted to conventional EGD with no previous history for MDP evaluation. Although the cap can be easily fitted to the tip of the endoscope and is a low-cost alternative, it is usually associated with specific therapeutic or diagnosis purposes, and its use is commonly limited to cases of MDP evaluation in patients with suspected MDP lesion or at high risk for MDP lesions. The disadvantage of our technique is the use of the biopsy forceps, which in spite of its low cost, as occurs with the caps, represents an extra expense in the search for a lesion that is not considered highly prevalent. 
The forward-viewing gastroscopy and the biopsy forceps are the two most basic tools for the development of the endoscopic study of the upper GIT, and are available in all endoscopy services in the world. Therefore, the active search for MDP with this technique can be carried out in virtually all routine procedures, and not exclusively in those with indication for the study of MDP. Considering that in 2010, only in the US, there were 2,895,999 conventional EGD carried out ${ }^{(12)}$, the use of the biopsy forceps as an auxiliary technique in the examination of the MDP would enable a full evaluation of the MDP in $90 \%$ of the upper digestive endoscopies carried out in the world. Such practice would definitely increase the detection of small MDP lesions, which would enable not only early diagnosis, but also their endoscopic treatment, resulting in less morbidity and mortality to patients ${ }^{(13)}$.

\section{CONCLUSION}

The use of the biopsy forceps as an auxiliary technique to the straightening maneuver in the active search for the MDP with forward-viewing conventional gastroscopy has significantly increased the full MDP visualization rate $(P<0.01)$ and can be easily incorporated to routine GI endoscopic examinations.

\section{Authors' contributions}

Andrade NS: data collected and manuscript elaboration. André AMF: data collected. Ferreira VHP: manuscript elaboration. Ferreira LEVVC: data collected, manuscript elaboration and protocol elaboration.

Andrade NS, André AMF, Ferreira VHP, Ferreira LEVVC. O uso da pinça de biópsia como técnica auxiliar na visualização da papila duodenal maior utilizando-se o esofagogastroduodenoscópio de visão frontal. Arq Gastroenterol. 2018;55(1):46-9.

RESUMO - Contexto - Esofagogastroduodenoscopia convencional é o melhor método para avaliação do trato gastrointestinal superior, mas apresenta limitações para identificação da papila duodenal maior, mesmo após emprego da manobra de retificação. Exame completo da papila duodenal maior está indicado para pacientes de alto risco para adenocarcinoma da papila duodenal maior. Objetivo - Avaliar a utilização da pinça de biópsia durante esofagogastroduodenoscopia convencional como ferramenta adicional à manobra de retificação na avaliação da papila duodenal maior. Métodos Foram estudados 671 pacientes entre 2013-2015 com busca ativa da papila duodenal maior em três etapas: endoscópio não retificado, endoscópio retificado e uso da pinça de biópsia após retificação. Em todas se registrou: se a papila duodenal maior foi totalmente visualizada (posição A), se parcialmente visualizada (posição B) ou se não visualizada (posição C). Caso a papila duodenal maior não tenha sido completamente visualizada, o paciente foi direcionado para a etapa seguinte. Resultados - Um total de 341 era do sexo feminino (50,8\%) com idade média de 49 anos. Dos 671 pacientes, em $324(48,3 \%)$ a papila duodenal maior foi identificada na posição A, 112 (16,7\%) em posição B e, 235 (35\%) em posição C. Dos 347 pacientes submetidos à manobra de retificação, posição $\mathrm{A}$ foi encontrada em $186(53,6 \%)$, posição $\mathrm{B}$ em $51(14,7 \%)$ e posição $\mathrm{C}$ em 110 (31,7\%). Dos 161 pacientes restantes que utilizaram a pinça de biópsia, posição A foi vista em 94 (58,4\%), posição B em 14 (8,7\%) e posição C em 53 (32,9\%). A taxa acumulativa de visualização completa da papila duodenal maior foi de $90 \%$. Conclusão - O uso da pinça de biópsia aumentou a taxa de visualização completa da papila duodenal maior em $14 \%$, alcançando $604 / 671(90 \%)$ dos pacientes $(P<0,01)$ avaliados e pode ser facilmente incorporada aos exames endoscópicos de rotina do trato gastrointestinal superior.

DESCRITORES - Ampola hepatopancreática, fisiopatologia. Adenocarcinoma, diagnóstico. Endoscopia do sistema digestório, utilização.

\section{REFERENCES}

1. Hew WY, Joo KR, Cha JM, Shin HP, Lee JI, Park JJ, Lim JU. Feasibility of forward-viewing upper endoscopy for detection of the major duodenal papilla. Dig Dis Sci. 2011;56:2895-9.

2. Syngal S, Brand RE, Church JM, Giardiello FM, Hampel HL, Burt RW; American College of Gastroenterology. American College of Gastroenterology. ACG clinical guideline: Genetic testing and management of hereditary gastrointestinal cancer syndromes. Am J Gastroenterol. 2015;110:223-62.

3. ASGE Standards of Practice Committee, Chathadi KV, Khashab MA, Acosta RD, Chandrasekhara V, Eloubeidi MA, et al. The role of endoscopy in ampullary and duodenal adenomas. Gastrointest Endosc. 2015;82:773-81.

4. Abdelhafez M, Phillip V, Hapfelmeier A, Elnegouly M, Poszler A, Strobel K., et al. Cap Assisted Upper Endoscopy for Examination of the Major Duodena Papilla: A Randomized, Blinded, Controlled Crossover Study (CAPPA Study). Am J Gastroenterol. 2017;112:725-33.

5. Choi YR, Han JH, Cho YS, Han HS, Chae HB, Park SM, Youn SJ. Efficacy of cap-assisted endoscopy for routine examining the ampulla of Vater. World J Gastroenterol. 2013;19:2037-43
6. Cohen LB, Delegge MH, Aisenberg J, Brill JV, Inadomi JM, Kochman ML, et al. AGA Institute review of endoscopic sedation. Gastroenterology. 2007;133:675-701.

7. Demirturk L, Tanoglu A, Oztek I. Vascular hamartomatous lesion of the ampulla of Vater: a very uncommon occurrence. Gastrointest Endosc. 2014;80:347-8.

8. El Hajj II, Coté GA. Endoscopic diagnosis and management of ampullary lesions. Gastrointest Endosc Clin N Am. 2013;23:95-109.

9. Hoshimoto S, Aiura K, Shito M, Kakefuda T, Sugiura H. Adenosquamous carcinoma of the ampulla of Vater: a case report and literature review. World $\mathrm{J}$ Surg Oncol. 2015;13:287.

10. Kim HK, Lo SK. Endoscopic approach to the patient with benign or malignant ampullary lesions. Gastrointest Endosc Clin N Am. 2013;23:347-83.

11. Avisse C, Flament JB, Delattre JF. Ampulla of Vater. Anatomic, embryologic, and surgical aspects. Surg Clin North Am. 2000;80:201-12.

12. Peery AF, Dellon ES, Lund J, Crockett SD, McGowan CE, Bulsiewicz WJ, et al. Burden of gastrointestinal disease in the United States: 2012 update. Gastroenterology. 2012;143:1179-87.e1-3.

13. de Palma GD. Endoscopic papillectomy: indications, techniques, and results. World J Gastroenterol. 2014;20:1537-43. 